\title{
ACQUIRED PANDIGITAL CLUBBING
}

Soumya Samuel ${ }^{1}$, K. Kamalakannan², P. Arun Prasath ${ }^{3}$, K. Srivenkateswaran ${ }^{4}$

\section{HOW TO CITE THIS ARTICLE:}

Soumya Samuel, K. Kamalakannan, P. Arun Prasath, K. Srivenkateswaran. "Acquired Pandigital Clubbing". Journal of Evolution of Medical and Dental Sciences 2015; Vol. 4, Issue 39, May 14; Page: 6901-6903, DOI: $10.14260 /$ jemds/2015/1002

INTRODUCTION: A 54 years old man, a chronic smoker, for more than 20 years, presented with symmetrical bulbar swelling of terminal segments of all digits of one year duration [Figures 1 and 2], with loss of Lovibond's angle and obliteration of Schamroth's window. He also had symptoms of dry cough and exertional dyspnoea. Finger nails showed classical parrot beak appearance [Figure 3], while in the toe nails, the changes were less marked. There was onychodystrophy of the right great toe nail, probably because of the abnormal nail curvature and recurrent trauma.

A clinical diagnosis of acquired pandigital clubbing was entertained. Chest X-ray showed features suggestive of interstitial lung disease (ILD) and a high resolution chest CT scan was suggested to rule out ILD, however patient was lost to follow up.

Clubbing was first described by Hippocrates in a patient with empyema, and hence is also described as Hippocratic finger.[1] It is characterized by increased nail plate curvature longitudinally and transversely with soft tissue hypertrophy of the digital pulp usually involving all 20 digits.[2] Common associations include cyanotic congenital heart diseases, infective endocarditis, primary and metastatic lung cancer, suppurative lung diseases, interstitial lung diseases (ILD), inflammatory bowel disease and hepatic cirrhosis. ILD is frequently associated with digital clubbing and among ILD, most common association is noted in idiopathic pulmonary fibrosis. ${ }^{[3]}$

Clubbing may occur as a part of hypertrophic osteoarthropathy (HOA) which may be primary or secondary. Primary HOA or pachydermoperiostosis is a rare hereditary disorder characterized by digital clubbing, subperiosteal new bone formation, acro-osteolysis, hypertrophy of soft tissues and glands, particularly in the face and scalp resulting in wrinkling of skin. ${ }^{[4]}$ Secondary HOA is in general associated with pulmonary malignancy and suppurative lung diseases.

\section{REFERENCES:}

1. Hippocrates. Prognostic. In: Jones WH. Hippocrates. 1st ed, Vol II. London: Loeb Classical Library, No. 148, William Heinemann ltd; 1923. p. 7-55. Available from: http://www.archive.org/details/hippocrates02hippuoft

2. Singal A, Arora R. Nail as a window of systemic diseases. Indian Dermatol Online J 2015; 6: 6774.

3. Sarkar M, Mahesh DM, Madabhavi I. Digital clubbing. Lung India 2012; 29: 354-62.

4. Jajic I, Jajic Z, Grazio S. Minor but important symptoms and signs in primary hypertrophic osteoarthropathy. Clin Exp Rheumatol 2001; 19: 357-8. 


\section{IMAGES IN MEDICINE}

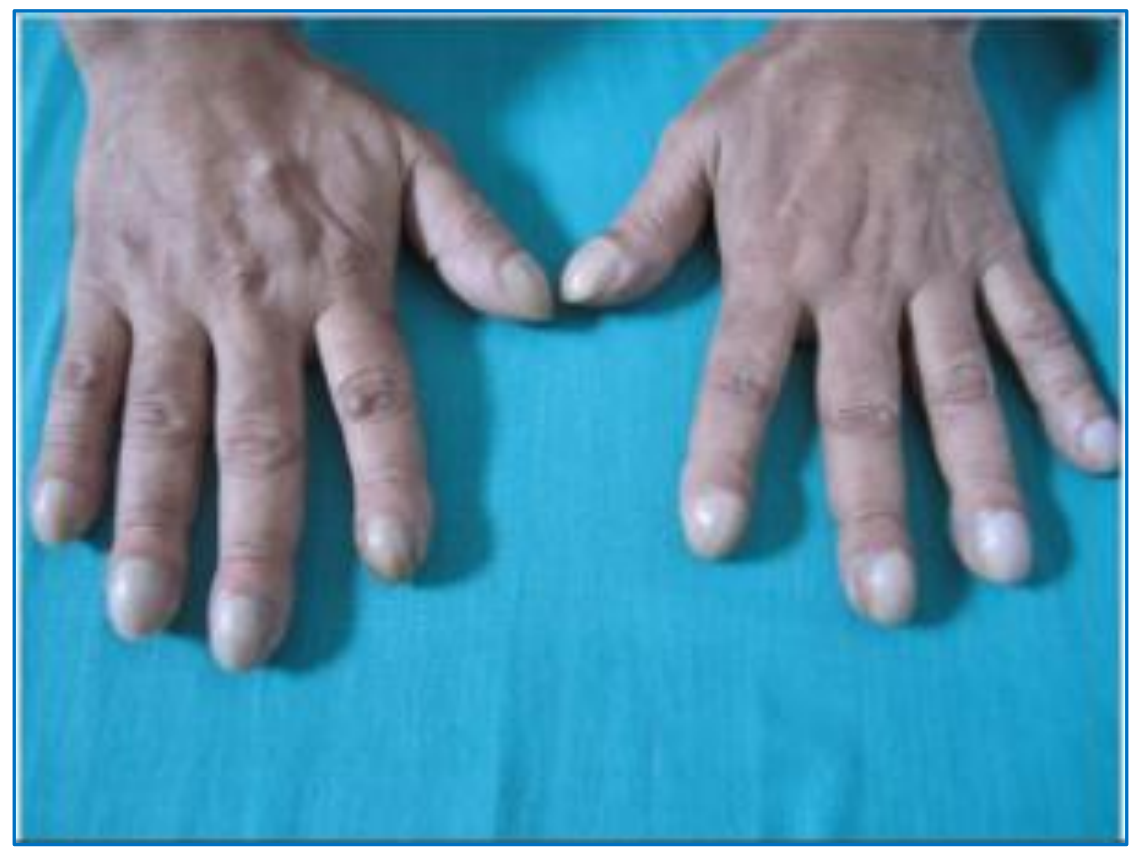

Fig. 1: Clubbing involving all fingers

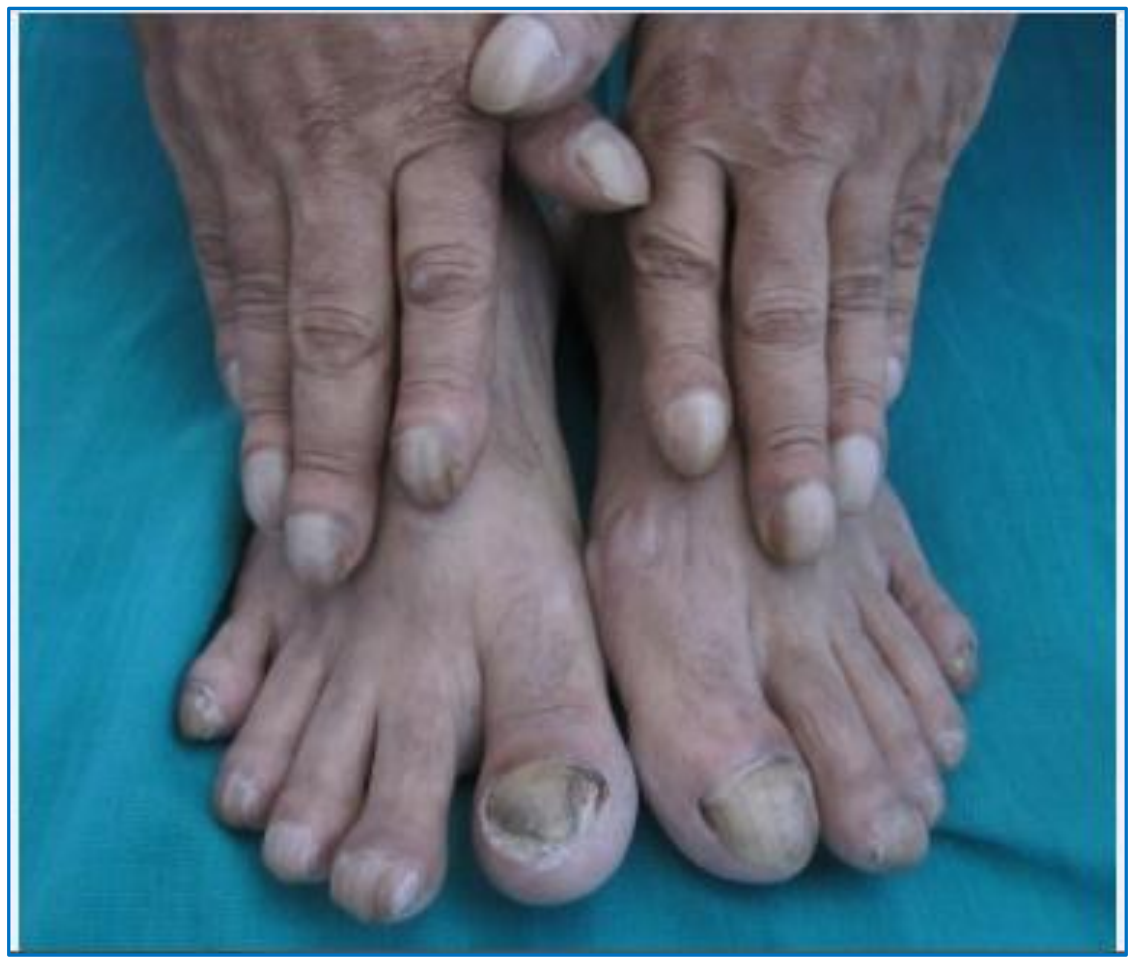

Fig. 2: Pandigital clubbing involving all 20 digits 


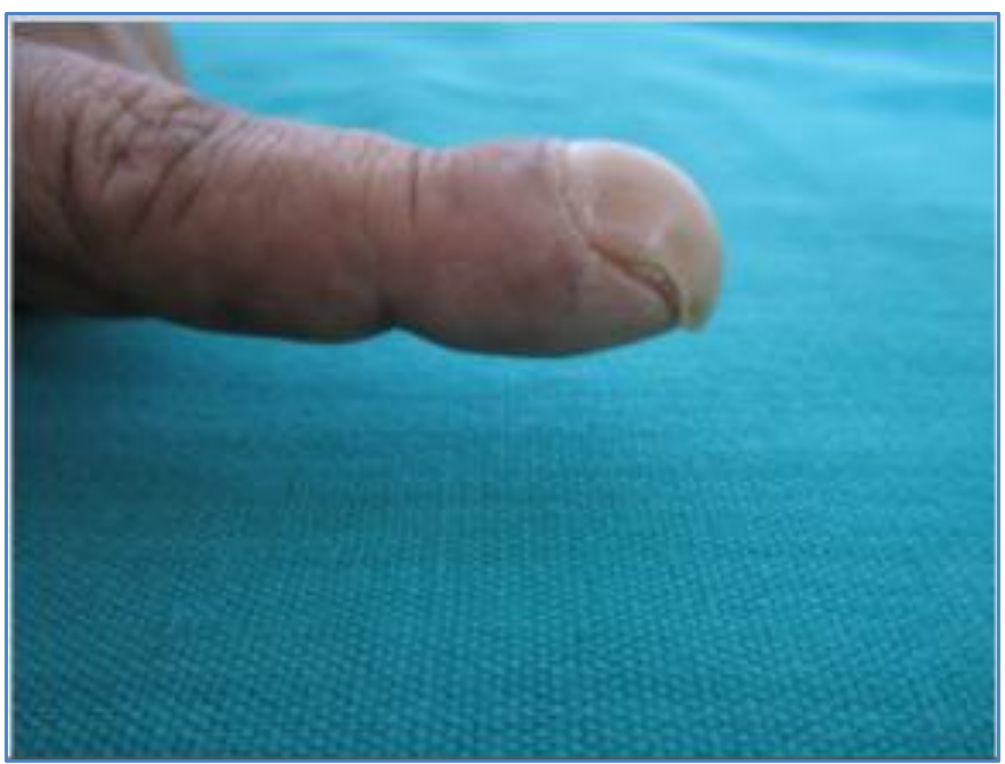

Fig. 3: Classical parrot beak appearance

\section{AUTHORS: \\ 1. Soumya Samuel \\ 2. K. Kamalakannan \\ 3. P. Arun Prasath \\ 4. K. Srivenkateswaran}

\section{PARTICULARS OF CONTRIBUTORS:}

1. Post Graduate, Department of Dermatology \& STD, Vinayaka Mission's Medical College \& Hospital, Keezhakasakudimedu, Karaikal, Pondicherry, India.

2. Assistant Professor, Department of Dermatology \& STD, Vinayaka Mission's Medical College \& Hospital, Keezhakasakudimedu, Karaikal, Pondicherry, India.

FINANCIAL OR OTHER COMPETING INTERESTS: None
3. Senior Resident, Department of Dermatology \& STD, Vinayaka Mission's Medical College \& Hospital, Keezhakasakudimedu, Karaikal, Pondicherry, India.

4. Professor, Department of Dermatology \& STD, Vinayaka Mission's Medical College \& Hospital, Keezhakasakudimedu, Karaikal, Pondicherry, India.

\section{NAME ADDRESS EMAIL ID OF THE CORRESPONDING AUTHOR:}

Dr. Soumya Samuel,

Post Graduate,

Department of Dermatology \& STD,

Vinayaka Mission's Medical College \& Hospital,

Karaikal-609609, Pondicherry, India.

E-mail: drsoumyasamuel@hotmail.com 